\title{
La memoria a debate. El grupo de discusión y mitos urbanos
}

Rossana Reguillo

CUCSH-UDEG

En este texto se discuten algunos de los elementos teóricometodológicos de la investigación en curso "Mitologías urbanas: la construcción social del miedo". Se explora la dimensión de la memoria a partir de la utilización del grupo de discusión como dispositivo metodológico para producir "relatos (discursos analizables), concebidos en la investigación como punto de intersección entre la representación y la acción".

El descubrimiento de que el mundo se volvió mundo, de que el globo ya no es sólo una figura astronómica, de que la tierra es el territorio en el que todos nos encontramos relacionados y remolcados, diferenciados y antagónicos, ese descubrimiento sorprende, encanta y atemoriza. Se trata de una ruptura drástica en los modos de ser, sentir, actuar, pensar y fabular. Un evento heurístico de amplias proporciones, que estremece no sólo convicciones sino también visiones del mundo.

Octavio Ianni
A cabadas las labores del día, con unas horas para gastar en animadas conversaciones, alrededor del comal, los tíos, los abuelos, los primos, los padres, los hijos y los nietos se reunían para contar y escuchar, para enseñar y aprender, para reírse o asustarse hasta palidecer y, sobre todo, para entender la vida. Cuando los días en que el tiempo se medía por los ciclos de cosecha y recolección, por los ciclos de vida y muerte, había tiempo para narrar, para transmitir de voz en voz, de generación en generación, las historias que contaban los orígenes del país, que recuperaban las hazañas de 
los héroes que hoy no aparecen en los libros de texto, para exorcizar los males, para darle forma a los milagros, cuerpo a los aparecidos y un orden a cada cosa.

Los avisos de tesoros enterrados, las apariciones de ánimas en pena en busca de almas caritativas que rezaran por su salvación, los espíritus malignos, los muertos de muerte mala que tentaban a los cristianos en las encrucijadas de los caminos, el mismísimo chamuco que sin previo aviso se aparecía en las veredas para asustar desprevenidos. Robadores profesionales de almas y restablecedores de lo perdido; ángeles y demonios; blanco y negro, luz y oscuridad.

Poco a poco fue llegando la prisa que algunos llamaron modernización, quedaron para después los cuentos, las narraciones.

Pero la memoria no entiende de modernidades ni de escenarios, y rápidamente, alrededor de otros objetos, la televisión por ejemplo, la gente se agrupó para contar y escuchar. Se repitieron los viejos relatos, se encontraron nuevos para poner a prueba la valentía, la imaginación, la capacidad narrativa.

Domesticar los miedos, darle forma a las creencias, devolverle al mundo la magia y el encantamiento y proteger contra lo desconocido y amenazante, son algunas de las funciones que hoy cumplen los mitos y leyendas, que con contenidos diversos circulan en el entorno urbano.

\section{ALGUNOS SUPUESTOS}

La premisa básica que orienta la investigación en curso acerca de los mitos urbanos en el escenario de la modernidad mexicana, es que en la formulación, narración y circulación de "relatos", se ponen en funcionamiento visiones y valoraciones sobre el mundo, que se conectan a la dimensión de las identidades sociales en dos niveles: a) como identificación, en la medida en que el relato tiende a fijar las creencias de un grupo, de una colectividad, y b) como diferenciación, al resaltar algunos objetos, acontecimientos, relaciones, que vuelven visibles los huecos y discontinuidades y contradicciones en las percepciones diferenciadas del mundo.

El relato actualiza las identidades culturales al ser simultáneamente producto de unas particulares y específcas maneras de ver el mundo y productor de propuestas, de modelos a los cuales adscribirse. El relato puede entonces ser considerado como el punto de intersección entre representación y acción.

Es este último aspecto sobre el que interesa hacer énfasis, la dimensión productiva de los mitos, su capacidad de convocar, de interpelar, de provocar la discusión, es decir, su eficacia simbólica para el posicionamiento de los actores sociales en relación con los valores sociales (un mito siempre trata de valores) que el relato pone en juego.

Hoy día "nuestra sociedad está inquieta. Hay una inquietud, una angustia, crispada al fondo de nosotros". ${ }^{1}$

${ }^{1}$ Duby, Año, 1995, p. 13. 
Existen miedos que han acompañado a la humanidad a través de su largo viaje por la historia, sin embargo hoy

la razón parece incapaz de redimir después de tanta promesa, el castigo se revela mayor que el pecado. La utopía de la emancipación individual, colectiva, nacional, mundial, parece que está siendo castigada por la globalización tecnocrática, instrumental, mercantil, consumista. La misma razón que realiza el desencantamiento del mundo para así emanciparlo, enajena más o menos inexorablemente a todo el mundo. ${ }^{2}$

De un lado, el miedo, la angustia producida por la crisis social en todos los órdenes; de otro, el desencantamiento de un mundo al que parecían habérsele arrebatado todos sus secretos. La incertidumbre es la característica societal de fin de milenio.

$\mathrm{Y}$ entre las distintas formas de respuesta a la incertidumbre, al desencantamiento, a la angustia, al miedo, cobra fuerza la elaboración de relatos compartidos colectivamente (en función de distintas mediaciones, por ejemplo el género, la clase, la edad, la religiosidad, la ideología política, etc.) que proveen explicaciones e interpretaciones del mundo. Relatos que codifican las creencias de los grupos portadores y que inciden en las formas de socialidad.

Así lo que importa no es tanto el relato en sí mismo, como el contexto que hace posible su aparición y circulación, como las verdades que revela al poner en forma un (unos) miedo(s) difuso(s), y señalar las áreas de

${ }^{2}$ Ianni, Teorias, 1996, p. 10. vulnerabilidad y fragilidad que experimentan los actores sociales.

\section{DISPOSITIVOS METODOLÓGICOS}

Los diversos, los otros o el otro y el mí mismo, como dimensiones de la experiencia del actor se constituyen en el núcleo metodológico a partir del cual se ordenan los relatos producidos y sostenidos por diferentes colectivos $^{3}$ urbanos en tanto portadores de una identidad cultural.

Se busca que los colectivos seleccionados para la investigación produzcan discursos analizables a partir de los relatos compartidos intersubjetivamente. Tres son los criterios que orientan esta producción organizada de relatos: ${ }^{4}$

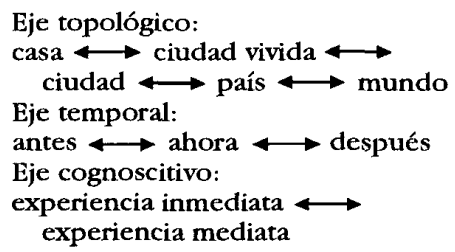
experiencia mediata

Cada uno de estos ejes y sus posteriores entrecruzamientos buscan pe-

${ }^{3}$ Se han seleccionado cinco matrices identitarias: luchadores sociales, homosexuales, jóvenes, empresarios, religiosos. Cada una de estas categorías encuentra su representación empírica en diferentes colectivos (diez en total). Para más detalles ver Reguillo, "Mitos", 1996.

${ }^{4}$ Esto no excluye el recurrir para el análisis a los documentos de los colectivos seleccionados: boletines, revistas, diarios íntimos, etc. $O$ recurrir a la información que sobre estos mismos colectivos circula por los medios de comunicación. 


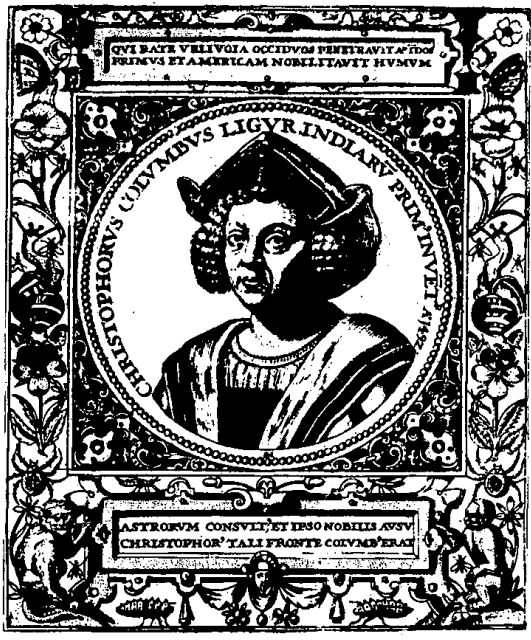

netrar hermenéuticamente los relatos. Lo que se espera se puede esquematizar de la siguiente manera:

El eje topológico permite analizar las relaciones entre lo público y lo privado, hoy día uno de los grandes debates en ciencias sociales. Además posibilita entender el espacio como una red de relaciones entre lo próximo y lo lejano al tiempo que devela sus diferencias o similitudes.

A través del eje temporal puede reconocerse la relación del actor con la colectividad y con la historia. El tiempo es un mecanismo de identificación y de alteridad, "nosotros los de antes", "ustedes los de ahora". Las imágenes que habitan el mundo de ayer y el mundo de mañana, asociados a los símbolos y valores.
Por su parte el eje cognoscitivo se ocupa del análisis de las fuentes que nutren los imaginarios sociales que van desde la experiencia cara a cara hasta las imágenes del mundo como espectáculo que presentan día a día los medios de comunicación, principalmente la televisión.

La investigación está planteada en tres etapas en lo que toca a formas de registro:

1) Fase de observación de los colectivos seleccionados y familiarización con su entorno y con sus códigos comunicativos.

2) Entrevistas a profundidad con los miembros del colectivo que serán seleccionados en función de la información que arroje la primera fase. En esta etapa se utilizarán también algunos "textos-relatos" claves (escritos o audiovisuales) a manera de reactivos.

3) Grupo de discusión. A partir de los resultados de la segunda fase, se selecciona un miembro de cada colectivo y se integra un grupo de discusión con diez participantes, la investigadora y un observador. Las sesiones grabadas en video (un mínimo de tres y un máximo de cinco) se organizan a partir de los elementos más significativos obtenidos de las entrevistas, pero articulados siempre a la tríada pluralidad-alteridad-identidad.

En esta ocasión interesa discutir los avances y los resultados parciales en la utilización metodológica de los grupos de discusión y su relación con los dispositivos de la memoria y de la identidad. 


\section{EL. GRUPO DE DISCUSIÓN}

El contexto existencial del discurso del "grupo de discusión" es un proceso de producción. El discurso del grupo es el producto de una producción, no de una recolección: en el discurso queda la memoria de las huellas de ese proceso...no hay técnica inocente. Jesús Ibáñez

Se han explicitado ya algunas de las líneas generales de la investigación en curso, queda añadir que en la etapa actual, se está procesando para su análisis el resultado de algunos grupos pilotos de discusión. Se refiere aquí la experiencia con un grupo de estudiantes universitarios.

Este grupo está compuesto por diez participantes, cinco mujeres y cinco hombres cuyas edades fluctúan entre los 20 y los 25 años, todos son estudiantes universitarios que comparten una situación socioeconómica afín; se trata de jóvenes de sectores medios urbanos. Sus orígenes son variados, provienen de distintas ciudades del país y sus familias se dedican a diferentes actividades; los hay profesionistas, comerciantes, agricultores.

Para cada sesión se cuenta con uno o dos observadores que registran to que sucede y retroalimentan posteriormente el análisis con sus notas sobre el desarrollo de la discusión; se utilizan dos cámaras de video, una graba los planos generales de la situación de interacción y la otra registra en planos cerrados las diferentes intervenciones de cada uno de los participantes, incluida la investigadora.

Pese a que en el grupo de discusión el diseño es (y debe ser) abierto

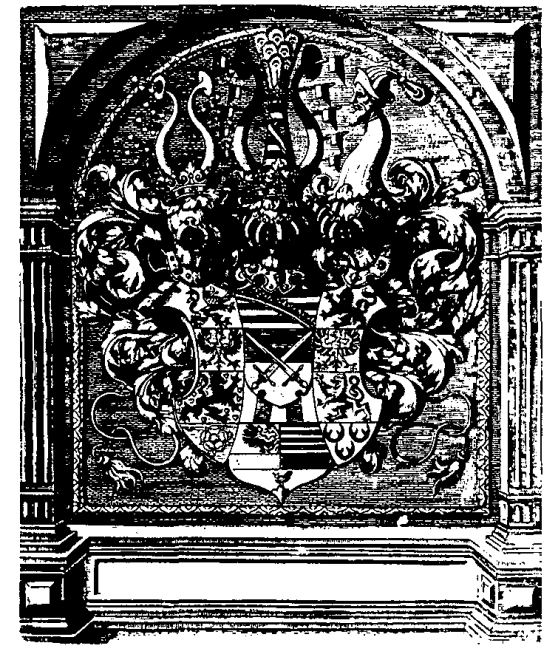

para permitir la integración de los sujetos en el proceso mismo de la investigación, hay algunas condiciones que deben garantizarse: la creación de unas coordenadas espacio-temporales donde el grupo (producido, ya que no estamos ante un grupo natural) adquiera tal estatuto y convenga en constituirse como tal durante el lapso que dure el ejercicio; tener claridad con respecto a los temas generadores o lo que aquí denomino el o los pretextos (es decir, antes del texto-relato que producirá el gŕupo). Los resultados obtenidos hasta el momento permiten afirmar que el grupo se constituye en una comunidad proxémica que va mutando conforme va produciendo discursos sobre el mundo. La convencionalidad, el acuerdo y los límites claros que el grupo asume, tien- 
den a aminorar los esencialismos identitarios con que los grupos suelen operar (nosotros creemos que, pensamos, sentimos) y posibilita el juego abierto de autopresentaciones y heteropercepciones entre los integrantes, pero al mismo tiempo acentúa la responsabilidad que cada uno de ellos cree tener al sentirse "representante" de una entidad mayor (su propio grupo de adscripción) en nombre de la cual habla y participa en el grupo.

\section{DESATAR LOS RECUERDOS}

Al inicio de la sesión la investigadora lanza de manera abierta la pregunta acerca de los recuerdos infantiles de los participantes en torno a los miedos y a las historias que escucharon durante su niñez.

Se producen risas y después un silencio, que será roto por una joven que con timidez dice: "yo de lo que más me acuerdo es de los pitufos diabólicos", y da comienzo a la narración de su experiencia. Conforme avanza, el grupo empieza a interesarse y a asentir gestualmente a la experiencia que está siendo narrada. Los turnos de palabra empiezan a sucederse.

Se pasa de completar el relato inicial a poner nuevos elementos a discusión: desde las muñecas que cobraban vida, las historias de aparecidos, a las figuras como el "robachicos" y la "gitana".

Poco a poco el grupo va encontrando las maneras de trascender el relato individual y de construir un registro

\footnotetext{
s Reguillo, "Lenguaje", 1996.
}

colectivo que va incorporando y matizando las diferencias: las que existen entre mujeres y hombres, entre familias conservadoras y menos conservadoras, entre regiones del país.

Mediante algunas intervenciones de la investigadora, que solicita un matiz aquí, una aclaración allá o lanza una provocación, se van estableciendo alianzas entre algunos de los participantes que se deshacen mediante las mismas intervenciones, para reencontrarse más adelante. Así el grupo se va autorregulando a través de la construcción discursiva de la experiencia, al reconstruir las fronteras entre la memoria individual y la memoria colectiva.

Ello significa que en el momento de producirse a sí mismo como una entidad discursiva, el grupo es capaz de poner en cuestión lo que Bossi ${ }^{6}$ ha denominado "versión consagrada de los acontecimientos" y hacer la crítica de las ideas dominantes.

En una palabra, en el grupo de discusión al detonarse la memoria (como imagen-recuerdo), se detonan procesos reflexivos. Al ponerse en evidencia lo que de colectivo tiene la experiencia individual, los sujetos entran en una dinámica de negociación de significados tanto con los otros sujetos como consigo mismos. Puede decirse que el discurso que va produciéndose se constituye en un instrumento para "pensar el pensamiento", 7 es decir, en un instrumento de reflexividad.

La memoria, desde esta perspectiva, deja de ser recuerdo de un "pasado idílico o catastrófico", que se "po-

\footnotetext{
${ }^{6}$ Bossi, "Memoria", 1990.
}

7 Ibáñez, Regreso, 1994. 
see" de una vez y para siempre, y aparece como la mediación que hace posible la crítica del orden social. No significa esto que se piense que el grupo de discusión "resuelve" las contradicciones de lo que Bourdieu ${ }^{8}$ ha llamado "la ilusión biográfica", vuelve visibles para los participantes, las operaciones, los procesos, las "chapuzas" en la presentación de los acontecimientos ligados a la propia vida.

\section{TRES PISTAS TRES}

Aunque por el estado de avance del proyecto es pronto para hacer afirmaciones, se adelantan algunos elementos como parte de un mapa provisorio que se está construyendo a partir de los resultados con los grupos de discusión.

\section{En el principio, "Había una vez..."} Pista 1: La familia de todos nosotros

Más allá de la relación entre familia y contexto (que debe ser tomada en serio), interesa aquí resaltar los mecanismos a través de los cuales el grupo familiar comunica a sus integrantes los valores y las normas sociales, tomando de un acervo colectivo aquellos elementos que le sirven para educar a sus miembros.

La figuras temidas, las historias y relatos para marcar las diferencias en-

"Bourdieu, "Ilusión".

${ }^{9}$ Según la cual, todo actor en situación de entrevista, tenderá a "representar" su vida como un todo coherente y a resaltar aquellos elementos "nobles" de su acción. tre lo bueno y lo malo, lo permitible y lo prohibido, lo sagrado y lo profano, etc., dan forma a un cuerpo de conocimientos sociales sólo transmisibles a través de un registro oral que alcanza su fuerza precisamente porque al desplegar su potencia explicativa en la forma de "mitos", oculta su intención prescriptiva y proscriptiva y aminora las resistencias del sujeto a medida que en su formulación se plantea una solución a la tensión entre verdad y mentira, o mejor dicho, ni siquiera se plantea esto como una oposición.

\section{Pista 2: La ciudad probibida}

En la narración oral del espacio escénico que los participantes recrean en el grupo de discusión, la ciudad deja de ser lugar de habitación, con calles, casas y plazas, con habitantes y servicios, y es antropomorfizada, se convierte en un actor capaz de "hacer cosas".

La ciudad es segmentada en partes y estas partes son semantizadas de acuerdo a la experiencia de los participantes. En el grupo de discusión aquí referido, resalta la pobreza de la experiencia urbana de los participantes, cuyo contacto con la ciudad es más vicario que de facto. Situación que se conecta directamente con lo mencionado respecto al grupo familiar, lugar desde el cual se controla y administra el uso que se hace de la ciudad en los primeros años de vida de los sujetos.

Las zonas pobres, los mercados populares, el centro histórico como lugares genéricos, y algunos lugares concretos, como cines, plazas, ciertas ca- 
lles, aparecen dotados de una peligrosidad a priori.

Es interesante hacer notar que la memoria de la ciudad se formula como una sucesión de puntos fijos, de lugares, y pocas veces como trayecto o desplazamiento. Como dato, como contenedora y no como producto de las acciones y decisiones humanas.

\section{Pista 3: El miedo al otro}

El "robachicos", la "gitana", - el desconocido, el extraño, actualizan las figuras que amenazan de múltiples formas la seguridad de los sujetos. Las coincidencias y las diferencias que en el grupo de discusión van revelando los participantes, ponen de manifiesto una gama muy reducida de "encarnaciones del mal".

Sin embargo, la construcción primaria (en el grupo familiar y en las primeras experiencias con los grupos de pares) del otro como enemigo, deja la memoria de un patrón que será luego "llenado" con las figuras del presente o, en otros términos, actualizado con nuevos miedos. Así, el homosexual, el practicante de alguna religión ajena a la del sujeto, los jóvenes pobres con ciertas marcas, lo que se presume es un narcotraficante, sustituyen al robachicos de manera aproblemática.

\section{NEGOCIAR IA MEMORIA}

Conforme avanza el desarrollo del grupo de discusión, los tres elementos que aquí se han seleccionado van su- friendo transformaciones importantes. Se mencionan algunas.

Por ejemplo, la centralidad de la familia como el lugar donde se construyen y se "procesan" las visiones del mundo, va adquiriendo una importancia clave. No se trata ya de la familia como dato empírico y específico de cada uno de los participantes, sino como instancia social cuyas funciones de control van apareciendo mediante el flujo discursivo.

A través de la discusión colectiva, para los participantes va quedando claro que el "relato" está ahí, puesto en escena, para que el sujeto no abandone la casa, no hable con extraños, incremente sus precauciones ante cierto tipo de actores, evite ciertas prácticas.

Se opera un desplazamiento de la memoria, de los recuerdos del contenido de los relatos, de las historias, hacia las situaciones en las que operaban estas historias.

De otro lado, la exploración colectiva de la precariedad de la experiencia urbana, abre, por ejemplo, un interesante y rico debate en torno a la relación entre memoria y espacio. Los participantes cuestionan el por qué son capaces de evocar "recuerdos" y asociarlos a un lugar determinado, sin haber estado nunca en esos lugares. Ello hace posible la crítica de los discursos sobre la ciudad.

Esto último directamente conectado con la existencia de los otros. Cada uno de los sujetos participa en el grupo de discusión con sus "propios otros". Al compartir los temores que inspiran ciertas figuras, se va revelando el conjunto de características, ras- 
gos, marcas, prácticas que "amenazan". El otro "homosexual", el otro "delincuente", el otro "pecador", adquieren visibilidad entonces, no como sujetos empíricos, sino como portadores de atributos sociales de carácter racial, religioso, sexual, socioeconómico, que los miembros del grupo de discusión, por su propia ubicación como actores históricamente situados, temen.

En ningún momento los participantes dicen "entonces... mis recuerdos estaban equivocados", sino, "entonces... a la luz de esta discusión, mis recuerdos adquieren otro sentido".

La copresencia convenida y pactada en el desarrollo del grupo de discusión permite que los sujetos exploren, a partir de las imágenes-recuerdos, el sentido de ciertas prácticas sociales, y pasen de las biografías individuales a una negociación colectiva de la memoria que ya no se presenta como dato monolítico y continuo, sino como proceso múltiple y discontinuo.

Los cambios operados en el mundo, que están reformulando la relación entre lo local y lo global, los acelerados procesos de interconexión, la velocidad y ubicuidad de la información, aunados a los paradójicos (y preocupantes) resurgimientos de ciertos fundamentalismos, el incremento de la intolerancia, de la violencia ciega, demandan entender por dónde pasan los miedos y las esperanzas, en tanto dispositivos de control social. La memoria como detonador de los procesos reflexivos, el grupo de discusión como palanca metodológica, constituyen una opción para el desmontaje crítico de las representaciones que operan como verdades absolutas. Esa es la apuesta.

\section{BIBLIOGRAFÍA}

-Barthes, Roland, Mitologías, Siglo XXI, México, 1981.

-Bossi, Eclea, "Memoria sueño y memoria trabajo", Culturas Contemporáneas VIII, Universidad de Colima, Programa Cultura, núms. 8-9, 1990, Colima.

-Bourdieu, Pierre, "La ilusión biográfica", trad. Hipólito Rodríguez, mimeo.

- y Loïs J.D. Wacquant, Respuestas. Por una antropología reflexiva, Grijalbo, México, 1995.

-Duby, Georges, Año 1000, año 2000. La buella de nuestros miedos, Editorial Andrés Bello, Santiago de Chile, 1995.

-Halbwachs, Maurice, "Espacio y memoria colectiva", Culturas Contemporáneas VIII, Universidad de Colima, Programa Cultura, núms. 8-9, 1990, Colima.

-Ianni, Octavio, Teorías de la globalización, Siglo XXI/UNAM, México, 1996.

-Ibáñez, Jesús, $E l$ regreso del sujeto. La investigación social de segundo orden, Siglo XXI, Madrid, 1994. Más allá de la sociología. El grupo de discusión: técnica y crítica, Siglo XXI, Madrid, 1979

-Reguillo, Rossana, "Los lenguajes del miedo. ¿Nuevos escenarios, nuevos?", Renglones, ITESO, núm. 35, agosto-noviembre, 1996, Guadalajara.

, "Los mitos gozan de cabal salud. El horizonte de las creencias colectivas en la modernidad mexicana", Comunicación y Sociedad, Universidad de Guadalajara, núm. 27, mayo-agosto, 1996, Guadalajara.

-Valenzuela, José Manuel (comp.), Entre la magia y la bistoria, CNCA/COLEF, México, 1992. 


\section{SECUENCIA}

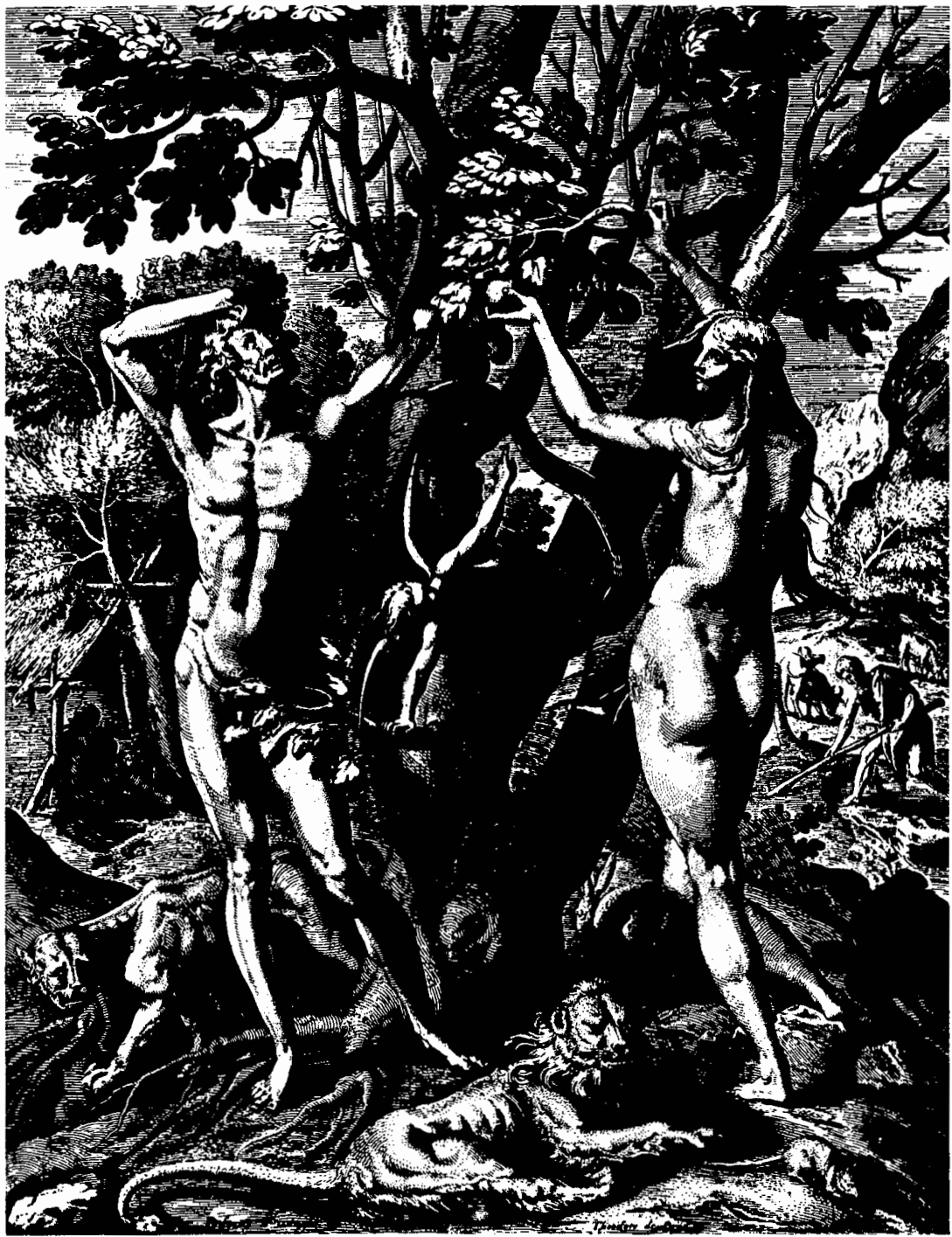

